\title{
Effects of co-existing anions on fluoride removal in electrocoagulation (EC) process using aluminum electrodes
}

\author{
C.Y. Hu ${ }^{\mathrm{a} *}$, S.L. Lo ${ }^{\mathrm{a}}$, W.H. Kuan ${ }^{\mathrm{b}}$ \\ ${ }^{a}$ Graduate Institute of Environmental Engineering, National Taiwan University, No. 71 Chou-shan Road, Taipei 106, Taiwan, ROC \\ ${ }^{\mathrm{b}}$ Department of Environmental And Safety Engineering, Ming-Chi Institute of Technology, Taishan, Taipei hsien 243, Taiwan, ROC
}

Received 9 January 2003; received in revised form 18 June 2003; accepted 22 June 2003

\begin{abstract}
Batch experiments with bipolar aluminum electrodes and potentiodynamic polarization tests with monopolar systems were conducted to investigate the effects of the type and concentration of co-existing anions on defluoridation in electrocoagulation (EC) process. The results demonstrate that the type of the dominant anion directs the EC defluoridation reaction. The defluoridation efficiency was almost $100 \%$ and most of the fluoride removal reaction occurred on the surface of the anode in the solution without the co-existing anions, due to the electro-condensation effect. In the solutions with co-existing anions, most of the defluoridation took place in bulk solution. The residual fluoride concentration is a function of the total mass of $\mathrm{Al}$ (III) liberation from anodes and the types of the functions in the solutions with and without co-existing anions are different. The existence of sulfate ions inhibits the localized corrosion of aluminum electrodes, leading to lower defluoridation efficiency because of lower current efficiency. The presence of chloride or nitrate ions prevented the inhibition of sulfate ions, and the chloride ions were more efficient. Different corrosion types occurred in different anion-containing solutions and the form of corrosion affected the kinetic over-potential. The bypass flow causes the decrease of current efficiency and the proportion of the bypass flow of current increased due to a rise of the kinetic over potential and the conductivity of the solution.
\end{abstract}

(C) 2003 Elsevier Ltd. All rights reserved.

Keywords: Aluminum; Bipolar electrodes; Co-existing anion; Corrosion; Defluoridation; Electrocoagulation (EC); Fluoride; Potentiodynamic polarization test

\section{Introduction}

Treating fluoride-containing wastewater has been an important issue following the development of the semiconductor industry. Dental fluorosis or skeletal damage may occur if the concentration of fluoride ions in drinking water exceeds $1.5 \mathrm{mg} / \mathrm{L}$ [1-4]. Currently, the cheapest way to remove fluoride ions from wastewater is to form calcium fluoride $\left(\mathrm{CaF}_{2}\right)$ by adding excess lime or other calcium salts $[5,6]$. This approach, however, raises the problem of the hardness of the water and reduces the reusability of wastewater. The theoretical fluoride

\footnotetext{
*Corresponding author. Tel.: + 886-927784672; fax: + 886-223928821.

E-mail address: chingyaohu@yahoo.com.tw (C.Y. Hu).
}

concentration calculated from the $K_{\mathrm{sp}}$ of $\mathrm{CaF}_{2}$ $\left(4 \times 10^{-12} \mathrm{M}^{3}\right)$ is $8-12 \mathrm{mg} / \mathrm{L}$, determined by adding stoichiometric amounts of calcium salt $[5,6]$. The treated water, however, frequently has a much higher concentration of fluoride because of slow nucleation, high ionic strength and a combination thereof [5-7]. Consequently, another defluoridation process must be performed after calcium precipitation to remove residual fluoride if stoichiometric amounts of calcium salt have been added.

Aluminum salt is a useful absorbent or coagulant for removing fluoride [5-8]. Coprecipitation (Eq. (1)) or adsorption (Eq. (2)) reaction may occur when aluminum salt is added to a fluoride-containing solution:

$$
\begin{aligned}
& n \mathrm{Al}_{(\mathrm{aq})}^{3+}+3 \mathrm{n}-\mathrm{mOH}_{(\mathrm{aq})}^{-}+m \mathrm{~F}_{(\mathrm{aq})}^{-} \\
& \quad \rightarrow \mathrm{Al}_{n} \mathrm{~F}_{m}(\mathrm{OH})_{3 n-m(\mathrm{~s})}
\end{aligned}
$$




\begin{tabular}{|c|c|c|c|}
\hline & $\mathrm{m}_{\mathrm{Al}(\mathrm{T})}$ & theoretical mass of $\mathrm{Al}(\mathrm{III})$ liberation $(\mathrm{kg})$ \\
\hline \multicolumn{2}{|c|}{$\begin{array}{l}\text { Nomenclature } \\
A \quad \text { active anode surface }\left(\mathrm{m}^{2}\right)\end{array}$} & $n$ & cells number ( $n=6$ in all systems) \\
\hline \multicolumn{2}{|c|}{$D \quad$ distance between electrodes $(\mathrm{m})$} & $t$ & reaction time (s) \\
\hline \multirow{3}{*}{\multicolumn{2}{|c|}{$\begin{array}{ll}{\left[\mathrm{F}^{-}\right]_{0}} & \text { initial fluoride concentration }\left(\mathrm{kg} \mathrm{m}^{-3}\right) \\
{\left[\mathrm{F}^{-}\right]_{\mathrm{f}}} & \text { final fluoride concentration }\left(\mathrm{kg} \mathrm{m}^{-3}\right) \\
{\left[\mathrm{F}^{-}\right]_{\mathrm{res}}} & \text { residual fluoride concentration }\left(\mathrm{kg} \mathrm{m}^{-3}\right)\end{array}$}} & $Z$ & valence $(Z=3$ for aluminum) \\
\hline & & $\varepsilon_{\mathrm{c}}$ & current efficiency $(\%)$ \\
\hline & & $\varepsilon_{\mathrm{F}}$ & defluoridation efficiency $(\%)$ \\
\hline \multirow{2}{*}{\multicolumn{2}{|c|}{$\begin{array}{ll}E_{\mathrm{AP}} & \text { applied potential }(\mathrm{V}) \\
\Delta E & \text { reaction potential }(\mathrm{V})\end{array}$}} & $\eta_{\mathrm{ak}}$ & anodic kinetic over potential (V) \\
\hline & reaction potential $(\mathrm{V})$ & $\eta_{\mathrm{am}}$ & anodic mass-transfer over potential $(\mathrm{V})$ \\
\hline \multicolumn{2}{|c|}{$\Delta E^{0} \quad$ standard reaction potential $(\mathrm{V})$} & $\eta_{\mathrm{ck}}$ & cathodic kinetic over potential (V) \\
\hline \multicolumn{2}{|c|}{$F \quad$ faraday constant, $F=96487\left(\mathrm{C} \mathrm{mol}^{-1}\right)$} & $\eta_{\mathrm{cm}}$ & cathodic mass-transfer over potential $(\mathrm{V})$ \\
\hline \multicolumn{2}{|c|}{$I \quad$ current $(\mathrm{A})$} & $\eta_{\mathrm{s}}$ & potential drop of solution $(\mathrm{V})$ \\
\hline \multirow{2}{*}{\multicolumn{2}{|c|}{$\begin{array}{l}\text { current density }\left(\mathrm{A} \mathrm{m}^{-2}\right) \\
\text { real mass of } \mathrm{Al}(\mathrm{III}) \text { liberation }(\mathrm{kg})\end{array}$}} & $\eta_{\mathrm{k}}$ & kinetic over potential of the electrode $(\mathrm{V})$ \\
\hline & & $\kappa$ & specific conductivity $\left(\Omega^{-1} \mathrm{~m}^{-1}\right)$ \\
\hline
\end{tabular}

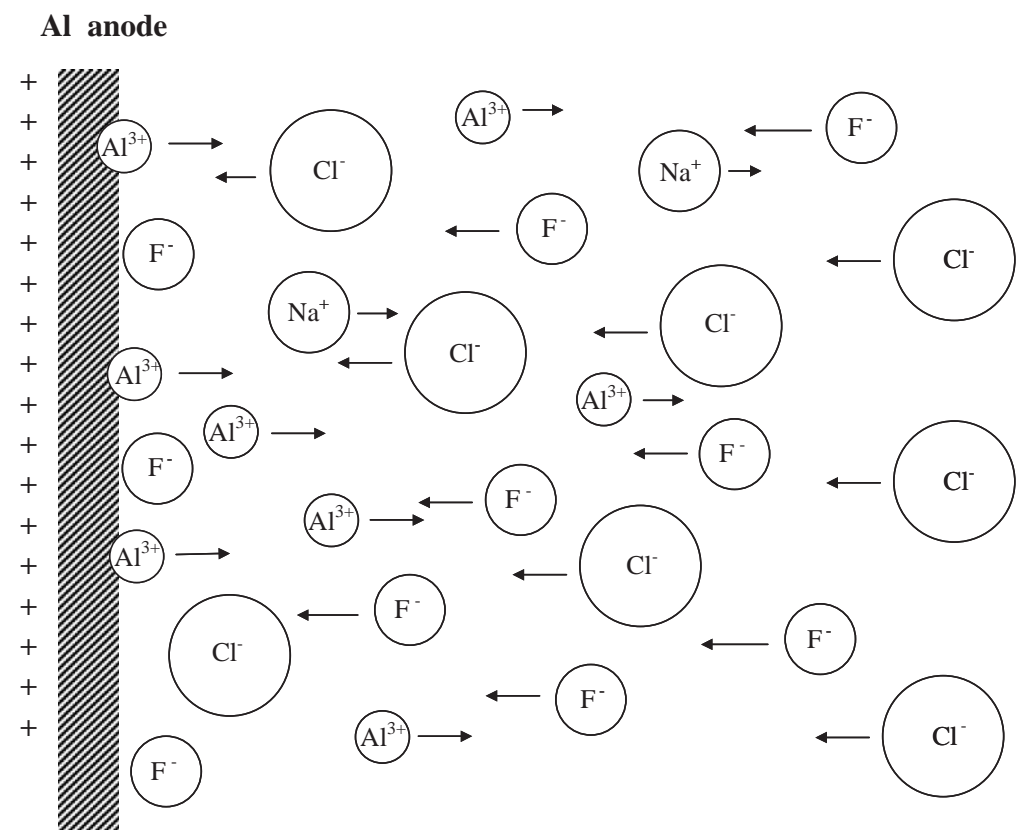

Fig. 1. Diagram of the electro-condensation effect. Anions would be attracted to the anode due to the electric force, and the concentration of anions near the anode would be higher than in bulk solution.

$$
\begin{aligned}
& \mathrm{Al}_{n}(\mathrm{OH})_{3 n(\mathrm{~s})}+m \mathrm{~F}_{(\mathrm{aq})}^{-} \\
& \quad \rightarrow \mathrm{Al}_{n} \mathrm{~F}_{m}(\mathrm{OH})_{3 n-m(\mathrm{~s})}+m \mathrm{OH}_{(\mathrm{aq})}^{-} .
\end{aligned}
$$

The fluoride removal efficiency of a fixed amount aluminum salt depends on $\mathrm{pH}$, alkalinity, the type of the co-existing anions, and other characteristics of the treated water. Hao et al. [9] stated that increase of the concentration of sulfate and other anions, which have a strong affinity with $\mathrm{Al}(\mathrm{III})$, decreases the adsorption capacity of fluoride onto hydrous alumina. This competition effect may also reduce the efficiency of defluoridation in other process using $\mathrm{Al}(\mathrm{III})$.

An electrochemical technique (electrocoagulation, EC) has been applied to produce $\mathrm{Al}(\mathrm{III})$ with an aluminum anode $[10,11]$ and a process with bipolar electrodes has been used to reduce the consumption of energy [12]. Liu et al. [10] reported that the defluoridation efficiency in the EC system exceeded that of the traditional process due to the electro-condensation effect. As shown in Fig. 1, the fluoride ions are attracted to the anode by the electric force and the fluoride concentration near the anode is higher than in the bulk 
solution. However, most of the fluoride ions attracted to the anode are replaced by other anions, if fluoride is not the dominant anion in solution. Therefore, the defluoridation efficiency may decline because of the present of co-existing anions.

The existence of passive oxide films is one of the main problems of the EC process $[13,14]$. Aluminum is a very reactive metal and owes its stability in normal environments to a protective oxide film. The film, however, increases the applied potential and leads to a waste of energy in the EC process. Directly measuring the composition of the passive film is difficult because it is so thin that making chemical or electrochemical measurements may change the structure and properties of the film [15]. Most of the researchers are interested in the passivity of the film, because it determines the corrosion rate in a certain applied potential. The most common way to characterize the passivity of a passive film involves the potentiodynamic polarization test. This method scans the rate of corrosion at various applied potentials to determine the passivity of the layer in various oxidation-reduction states by using a monopolar system.

The types of anions in treated water affect the passivity and other chemical properties of the film [1618]. Carroll et al. [17] employed potentiodynamic polarization test to elucidate the corrosion behavior of aluminum in solutions that contain both chloride and fluoride. They observed that the presence of fluoride ions modifies the oxide layer facilitating the localized attack by chloride. However, their experiments were conducted in a very strong $\mathrm{Cl}^{-}$concentration $(0.5 \mathrm{M})$, which is much higher than the $\mathrm{Cl}^{-}$concentration usually presented in EC defluoridation process, and the effects of other anions were not considered.

In summary, the type and concentration of co-existing anions play important roles in defluoridation in EC process. This work aims to elucidate the effects of various co-existing anions on defluoridation in EC process. Three kinds of common anion were tested to discern the effects of different co-existing anions. Monopolar and bipolar systems were used in potentiodynamic polarization tests and defluoridation experiments. The effects of co-exiting anions on the properties of passive films were examined by potentiodynamic polarization tests, and the effects on defluoridation efficiency, current efficiency and applied potential were quantified by bipolar defluoridation experiments.

\section{Materials and methods}

Table 1 shows the various experimental systems in this research. The objectives of systems 1 and 2 are to compare the effects of various types and concentrations of co-existing anions, respectively. Because $\mathrm{SO}_{4}^{2-}$ ion is
Table 1

The experimental systems for investigation of co-exiting anion effect

\begin{tabular}{ll}
\hline System & Types and concentrations of anions in solution \\
\hline 1 & $\mathrm{~F}^{-}(25 \mathrm{mg} / \mathrm{L})$ \\
& $\mathrm{F}^{-}(25 \mathrm{mg} / \mathrm{L})+\mathrm{Cl}^{-}(5 \mathrm{mM})$ \\
& $\mathrm{F}^{-}(25 \mathrm{mg} / \mathrm{L})+\mathrm{NO}_{3}^{-}(5 \mathrm{mM})$ \\
& $\mathrm{F}^{-}(25 \mathrm{mg} / \mathrm{L})+\mathrm{SO}_{4}^{2-}(5 \mathrm{mM})$ \\
& \\
& $\mathrm{F}^{-}(25 \mathrm{mg} / \mathrm{L})+\mathrm{Cl}^{-}(1 \mathrm{mM})$ \\
& $\mathrm{F}^{-}(25 \mathrm{mg} / \mathrm{L})+\mathrm{Cl}^{-}(10 \mathrm{mM})$ \\
& $\mathrm{F}^{-}(25 \mathrm{mg} / \mathrm{L})+\mathrm{NO}_{3}^{-}(1 \mathrm{mM})$ \\
& $\mathrm{F}^{-}(25 \mathrm{mg} / \mathrm{L})+\mathrm{NO}_{3}^{-}(10 \mathrm{mM})$ \\
& $\mathrm{F}^{-}(25 \mathrm{mg} / \mathrm{L})+\mathrm{SO}_{4}^{2-}(1 \mathrm{mM})$ \\
& $\mathrm{F}^{-}(25 \mathrm{mg} / \mathrm{L})+\mathrm{SO}_{4}^{2-}(10 \mathrm{mM})$ \\
& $\mathrm{F}^{-}(25 \mathrm{mg} / \mathrm{L})+\mathrm{SO}_{4}^{2-}(10 \mathrm{mM})+\mathrm{Cl}^{-}(1 \mathrm{mM})$ \\
& $\mathrm{F}^{-}(25 \mathrm{mg} / \mathrm{L})+\mathrm{SO}_{4}^{2-}(10 \mathrm{mM})+\mathrm{Cl}^{-}(10 \mathrm{mM})$ \\
& $\mathrm{F}^{-}(25 \mathrm{mg} / \mathrm{L})+\mathrm{SO}_{4}^{2-}(10 \mathrm{mM})+\mathrm{NO}_{3}^{-}(1 \mathrm{mM})$ \\
& $\mathrm{F}^{-}(25 \mathrm{mg} / \mathrm{L})+\mathrm{SO}_{4}^{2-}(10 \mathrm{mM})+\mathrm{NO}_{3}^{-}(10 \mathrm{mM})$ \\
\hline
\end{tabular}

one of the major factors that affect fluoride removal in the process that involves aluminum salts [9], the effects of $\mathrm{SO}_{4}^{2-}$ with other co-existing anions were investigated particularly in system 3 . The solutions of each system were prepared by a serial dilution of co-existing anions in $0.2 \mathrm{M}$ stock solutions and $1000 \mathrm{mg} / \mathrm{L}$ stock solution for $\mathrm{F}^{-}$ions. The stock solutions were prepared with reagent-grade chemicals and Millipore-Q water following standard methods.

\subsection{Bipolar defluoridation experiment}

The experiments were conducted in a bipolar batch reactor (as shown in Fig. 2) with seven aluminum electrodes connected in parallel, as used by Mameri et al. [12]. Only the outer electrodes were connected to the power source, and anodic and cathodic reactions occurred on each surface of the inner electrode when the current passed though the electrodes. The volume $(V)$ of the solution of each batch was $1 \mathrm{~L}$. The active area of each electrode, excluding the outer electrodes, was $8 \mathrm{~cm} \times 9 \mathrm{~cm}=72 \mathrm{~cm}^{2}$ and the dimensions of the outer electrodes $(7 \mathrm{~cm} \times 7 \mathrm{~cm})$ were reduced to prevent the electric field dispersing. Thus, the area/volume ratio of each batch was $40.9 \mathrm{~m}^{-1}$, higher than the required value reported by Mameri et al. [12]. The distance between each electrode was $1 \mathrm{~cm}$. A constant current (0.4 A) was maintained using a potentiostat in intensiostat mode. The current density was $8.16 \times 10^{-3} \mathrm{~A} / \mathrm{cm}^{2}$ for the outer electrode and $5.56 \times 10^{-3} \mathrm{~A} / \mathrm{cm}^{2}$ for the inner electrodes. Magnetic stirring at $400 \mathrm{rpm}$ maintained a homogeneous solution in the batch reactor. The temperature in each system was maintained at $25 \pm 1^{\circ} \mathrm{C}$. 


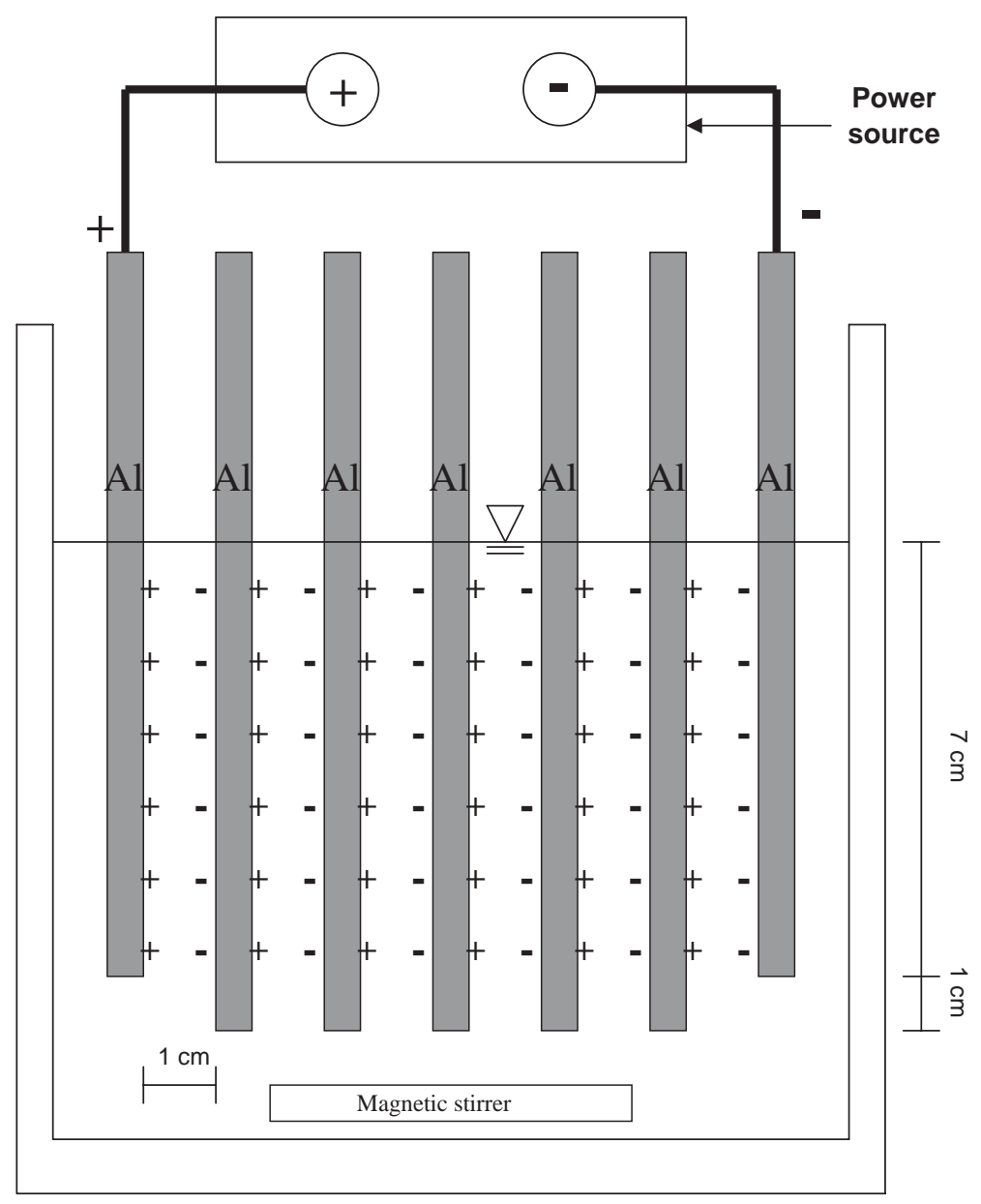

Fig. 2. Profile of the batch reactor.

Each reaction proceeded for $9 \mathrm{~min}$. Samples were extracted every minute and then immediately filtrated through a $0.2 \mu \mathrm{m}$ mixed cellulose ester membrane. The residual fluoride concentration $\left(\left[\mathrm{F}^{-}\right]_{\mathrm{res}}\right)$ including the finial fluoride concentration $\left(\left[\mathrm{F}^{-}\right]_{\mathrm{f}}\right)$ in each sample was determined by an ion chromatograph (Dionex, DX100). The initial fluoride concentration $\left(\left[\mathrm{F}^{-}\right]_{0}\right)$ in each system was $25 \mathrm{mg} /$ L. Eq. (3) defines the defluoridation efficiency $\left(\varepsilon_{\mathrm{F}}\right)$ in each batch:

$\varepsilon_{\mathrm{F}}=1-\left[\mathrm{F}^{-}\right]_{\mathrm{f}} /\left[\mathrm{F}^{-}\right]_{0}$.

After each reaction, the total concentration of $\mathrm{Al}(\mathrm{III})$ (Al(III) dosage) obtained from a digested sample (standard method, Section3030E) was measured using an atomic absorption spectrophotometer (Perkin Elmer, AAS 800) to determine the real mass of $\mathrm{Al}(\mathrm{III})$ liberation $\left(m_{\mathrm{Al}(\mathrm{R})}\right)$. The theoretical mass of $\mathrm{Al}(\mathrm{III})$ liberation $\left(m_{\mathrm{Al}(\mathrm{T})}\right)$ was calculated Faraday's law (Eq. (4)):

$m_{\mathrm{Al}(\mathrm{T})}=\frac{n \times I \times t \times M_{\mathrm{Al}}}{Z \times F}$.
Eq. (5) defines current efficiency as a ratio of the mass of liberated aluminum over the theoretical mass of liberated aluminum:

$\varepsilon_{\mathrm{c}}=m_{\mathrm{Al}(\mathrm{R})} / m_{\mathrm{Al}(\mathrm{T})}$.

\subsection{Potentiodynamic polarization test}

Potentiodynamic polarization tests were conducted on aluminum specimens exposed to various electrolytes as shown in Table 1 using a Galvanostat/ Potentiostat (Solartron, SI 1280B). Only the influence of types of coexisting anion was investigated because Carrol et al. [17] reported that the properties of the oxy-fluoride film on the anode surface seem to be independent on the concentration of anion in bulk solution. An area of $2.0 \mathrm{~cm}^{2}$ of each electrode was exposed to the test solution and the distance between the two electrodes was $2 \mathrm{~cm}$. A saturated calomel electrode (SCE) was used as the reference electrode. All experiments were performed at a scan rate of $0.5 \mathrm{mV} \mathrm{s}^{-1}$ from $-1.5 \mathrm{~V}_{\mathrm{SCE}}$ to 
$3.0 \mathrm{~V}_{\mathrm{SCE}}$, stirring at $400 \mathrm{rpm}$ at $25 \pm 0.1^{\circ} \mathrm{C}$. The specimens were washed in distilled water before reaction. After each test, the specimen was rinsed with deionized water and transferred to a SEM (Hitachi, S-2400) to obtain a microscopic image.

\section{Results and discussion}

\subsection{Effect on the defluoridation efficiency}

Table 2 shows the defluoridation efficiencies $\left(\varepsilon_{\mathrm{F}}\right)$, real mass of $\mathrm{Al}(\mathrm{III})$ liberation $\left(m_{\mathrm{Al}}\right)$, current efficiencies $\left(\varepsilon_{\mathrm{c}}\right)$, initial and final $\mathrm{pH}$ values and initial and final conductivity in various experimental systems. The $\varepsilon_{\mathrm{F}}$ was close to $100 \%$ in the absence of co-existing anions, dropping to $80-90 \%$ in the solutions that contained both $\mathrm{F}^{-}$and $\mathrm{Cl}^{-}$or $\mathrm{NO}_{3}^{-}$ions and dropping to $20-60 \%$ in the solution that contained both $\mathrm{F}^{-}$and $\mathrm{SO}_{4}^{2-}$ ions, respectively. It can be found in Table 2 that $\varepsilon_{\mathrm{F}}$ did not change very much with $\mathrm{Cl}^{-}$and $\mathrm{NO}_{3}^{-}$concentrations, but decreased as the concentration of $\mathrm{SO}_{4}^{2-}$ ions increased. The concentrations of $\mathrm{Cl}^{-}$and $\mathrm{NO}_{3}^{-}$seemed not to influence the defluoridation process but the concentration of $\mathrm{SO}_{4}^{2-}$ did. It might be due to the competition effect stated by Hao et al. [9].
As shown in Table 2, the values of $\varepsilon_{\mathrm{F}}$ increased with concentration of $\mathrm{Cl}^{-}$or $\mathrm{NO}_{3}^{-}$ions if there is a strong $\mathrm{SO}_{4}^{2-}$ concentration in solution. Moreover, the defluoridation efficiencies in solutions containing $\mathrm{F}^{-}, \mathrm{SO}_{4}^{2-}$ and $\mathrm{Cl}^{-}$ions were higher than in solutions containing $\mathrm{F}^{-}$, $\mathrm{SO}_{4}^{2-}$ and $\mathrm{NO}_{3}^{-}$ions. The lyotropic series of the anions for $\mathrm{Al}$ (III) is $\mathrm{F}^{-}>\mathrm{SO}_{4}^{2-} \gg \mathrm{Cl}^{-}>\mathrm{NO}_{3}^{-}$[19-23]. Therefore, the affinities of $\mathrm{Cl}^{-}$and $\mathrm{NO}_{3}^{-}$ions with $\mathrm{Al}(\mathrm{III})$ are too small to replace $\mathrm{F}^{-}$ions coordinating with $\mathrm{Al}(\mathrm{III})$. Sulfate ion, therefore, is the only possible species, which is able to replace $\mathrm{F}^{-}$ions coordinating with aluminum in system 3. The competition effect in the last solution of system 2 and solutions of system 3 should be almost the same because they have the same sulfate concentration. The defluoridation efficiencies in system 3, however, were greater than in the last solution of system 2, and changed with concentration of $\mathrm{Cl}^{-}$and concentration of $\mathrm{NO}_{3}^{-}$. Thus, the competition effect does not explain the fall of $\varepsilon_{\mathrm{F}}$ in the solutions containing both $\mathrm{F}^{-}$and $\mathrm{SO}_{4}^{2-}$ ions.

Fig. 3 displays images of the anode surface before and after EC defluoridation in the system without co-existing anions. A gelatinous deposition layer is present on the surface of the anode after EC reaction. Moreover, the deposited contained over $70 \%$ of the mass of liberated aluminum and the remnants may have been the parts of the layer lost due to the sheer force. The layer, however,

Table 2

The defluoridation efficiency $\left(\varepsilon_{\mathrm{F}}\right)$, real mass of $\mathrm{Al}(\mathrm{III})$ liberation $\left(m_{\mathrm{Al}}\right)$, current efficiency $\left(\varepsilon_{\mathrm{c}}\right)$, initial and finial $\mathrm{pH}\left(\mathrm{pH}_{\mathrm{i}}\right.$ and $\left.\mathrm{pH} \mathrm{f}_{\mathrm{f}}\right) \mathrm{values}$ and initial and finial conductivity $\left(\varepsilon_{\mathrm{i}}\right.$ and $\left.\varepsilon_{\mathrm{f}}\right)$ in system 1

\begin{tabular}{|c|c|c|c|c|c|c|c|c|}
\hline Types of co-existing anions & Concentration (mM) & $\varepsilon_{\mathrm{F}}(\%)$ & $m_{\mathrm{Al}}(\mathrm{mg})$ & $\varepsilon_{\mathrm{c}}(\%)$ & $\mathrm{pH}_{\mathrm{i}}$ & $\mathrm{pH}_{\mathrm{f}}$ & $\varepsilon_{\mathrm{i}}$ & $\varepsilon_{\mathrm{f}}$ \\
\hline \multicolumn{9}{|l|}{ System 1} \\
\hline None & - & 100.0 & 120.3 & 99.5 & 7.21 & 9.64 & 0.138 & 0.119 \\
\hline $\mathrm{Cl}^{-}$ & 5 & 87.1 & 146.8 & 125.4 & 5.23 & 8.98 & 0.725 & 0.713 \\
\hline $\mathrm{NO}_{3}^{-}$ & 5 & 85.0 & 141.9 & 117.4 & 5.78 & 9.16 & 0.697 & 0.679 \\
\hline $\mathrm{SO}_{4}^{2-}$ & 5 & 32.6 & 35.2 & 29.1 & 5.39 & 8.72 & 1.229 & 1.232 \\
\hline \multicolumn{9}{|l|}{ System 2} \\
\hline \multirow{2}{*}{$\mathrm{Cl}^{-}$} & 1 & 88.7 & 146.8 & 121.4 & 5.39 & 8.99 & 0.255 & 0.245 \\
\hline & 10 & 86.5 & 154.9 & 128.2 & 5.31 & 9.03 & 1.303 & 1.289 \\
\hline \multirow[t]{2}{*}{$\mathrm{NO}_{3}^{-}$} & 1 & 86.8 & 144.5 & 119.5 & 5.42 & 9.28 & 0.248 & 0.229 \\
\hline & 10 & 80.1 & 130.9 & 108.3 & 5.40 & 9.03 & 1.226 & 1.223 \\
\hline \multirow[t]{2}{*}{$\mathrm{SO}_{4}^{2-}$} & 1 & 67.3 & 97.4 & 80.5 & 5.26 & 9.27 & 0.378 & 0.402 \\
\hline & 10 & 21.1 & 29.4 & 24.3 & 5.39 & 8.66 & 2.220 & 2.210 \\
\hline \multicolumn{9}{|l|}{ System 3} \\
\hline \multirow[t]{2}{*}{$\mathrm{Cl}^{-}$} & 1 & 46.4 & 69.6 & 57.5 & 5.53 & 8.95 & 2.29 & 2.28 \\
\hline & 10 & 64.7 & 116.4 & 96.3 & 5.59 & 9.05 & 3.24 & 3.22 \\
\hline \multirow[t]{2}{*}{$\mathrm{NO}_{3}^{-}$} & 1 & 32.9 & 40.1 & 33.2 & 5.73 & 8.87 & 2.26 & 2.26 \\
\hline & 10 & 39.4 & 67.9 & 56.2 & 5.72 & 8.99 & 3.19 & 3.17 \\
\hline
\end{tabular}

$\left[\mathrm{F}^{-}\right]_{0}=25 \mathrm{mg} / \mathrm{L}$ in all systems; $\left[\mathrm{SO}_{4}^{2-}\right]=10 \mathrm{mM}$ in system 3. 


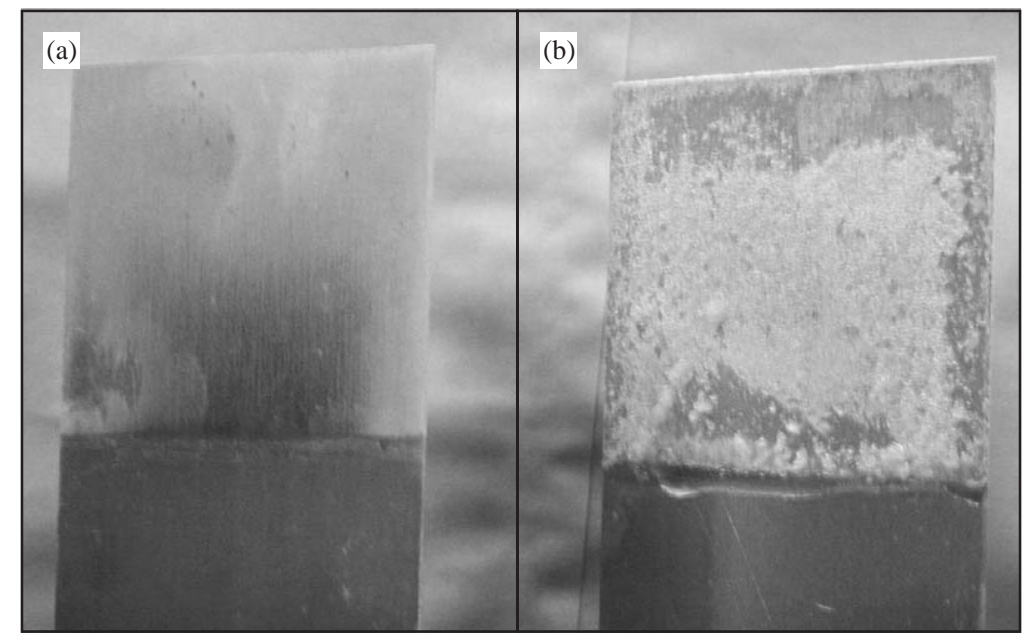

Fig. 3. The image of the anode surface (a) before and (b) after EC process in the system only containing fluoride ions.

was not found in other solutions. This finding demonstrates that most of the defluoridation takes place on the surface of the anode in the solution without co-existing anions, perhaps because of the electro-condense effect, which induces the accumulation of fluoride ions near the anode and leads to surface-coprecipitation on the anode. Most of the defluoridation reactions in the other systems occurred in bulk solution because most of the fluoride ions were replaced by the co-existing anions.

\subsection{Effect on the current efficiency and aluminum liberation}

As shown in Table $2, \varepsilon_{\mathrm{c}}$ was almost unity in the absence of co-existing anions, and exceeded $100 \%$ in the solution that contained both $\mathrm{F}^{-}$and $\mathrm{Cl}^{-}$or $\mathrm{NO}_{3}^{-}$ions, but was less than $100 \%$ in systems that contained both $\mathrm{F}^{-}$and $\mathrm{SO}_{4}^{2-}$ ions. Clearly, in the solution that contained both $\mathrm{F}^{-}$and $\mathrm{Cl}^{-}$or $\mathrm{NO}_{3}^{-}$ions, some reactions attributable to $\mathrm{Al}(\mathrm{III})$ liberation occurred, while in the systems that contained both $\mathrm{F}^{-}$and $\mathrm{SO}_{4}^{2-}$ ions, some reactions that restrained $\mathrm{Al}(\mathrm{III})$ liberation occurred. Mameri et al. [12] also observed a current efficiency in excess of $100 \%$ in the EC defluoridation process. They claimed that this efficiency could be explained by the "Pitting corrosion" phenomenon, which is a type of localized corrosion caused by a high chloride concentration in the solution. Foley [16] suggested that the localized corrosion of aluminum alloys involved four steps - (1) the local adsorption of reactive anions, such as $\mathrm{Cl}^{-}$ions, on the oxide film; (2) the chemical reaction of adsorbed anions with the $\mathrm{Al}(\mathrm{III})$ in the oxide film; (3) the thinning of the film by dissolution; (4) the direct attack of the exposed metal by water or anions (Eq. (6)).

$$
\begin{aligned}
& 2 \mathrm{Al}_{(\mathrm{s})}+6 \mathrm{H}_{2} \mathrm{O}_{(\mathrm{l})} \rightarrow 2 \mathrm{Al}(\mathrm{OH})_{3(\mathrm{~s})}+3 \mathrm{H}_{2(\mathrm{~g})} \\
& \Delta E^{0}=1.71 \mathrm{~V} .
\end{aligned}
$$

Obviously, reaction 6 increases the mass of aluminum liberated. Nitrate ions may lead to the same reactions as $\mathrm{Cl}^{-}$ions $[16,24]$ but the fluoride and $\mathrm{SO}_{4}^{2-}$ ions may not [25].

Fig. 4 plots the relationship between the residual fluoride concentration and the $\mathrm{Al}(\mathrm{III})$ dosage in the solutions containing various kinds of co-existing anions. The Al(III) dosage is equal to the real mass of $\mathrm{Al}(\mathrm{III})$ liberation over the volume of solution in EC process. All the data obtained from the solutions containing different kinds of co-exiting anions were distributed near to the line A. These results indicate that the residual fluoride concentration is a function of $\mathrm{Al}$ (III) dosage in all the solutions containing co-existing anions in the EC defluoridation process, and the type of the function does not change with the type and concentration of coexisting anions. Therefore, the decrease of $\varepsilon_{\mathrm{F}}$ in the solutions containing $\mathrm{SO}_{4}^{2-}$ ions and the rise of $\varepsilon_{\mathrm{F}}$ in system 3 were both due to the change of $\mathrm{Al}(\mathrm{III})$ dosage.

Fig. 4 also demonstrates that the data of the system without co-existing anions can be fitted as another function of $\mathrm{Al}(\mathrm{III})$ dosage (line B) and the slope of line $\mathrm{B}$ exceeds that of line $\mathrm{A}$, which fact can be explained by the electro-condensation effect. Buffle et al. [5] pointed that the $\left[\mathrm{F}^{-}\right] /\left[\mathrm{Al}^{3+}\right]$ ratio of the hydro-fluoro-aluminum precipitate at a high concentration of fluoride exceeds that at a low concentration of fluoride. As mentioned earlier, the fluoride concentration near the anode in the solution without co-existing anions is much higher than that in other solutions because of the 


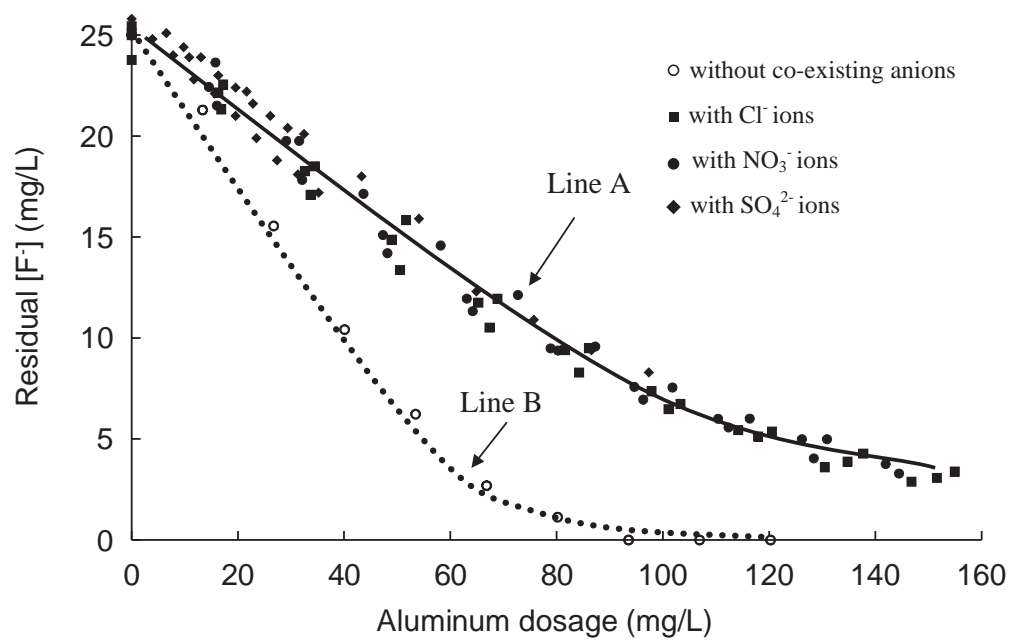

Fig. 4. The relationship between the residual fluoride concentration and $\mathrm{Al}(\mathrm{III})$ dosage with and without co-existing anions.

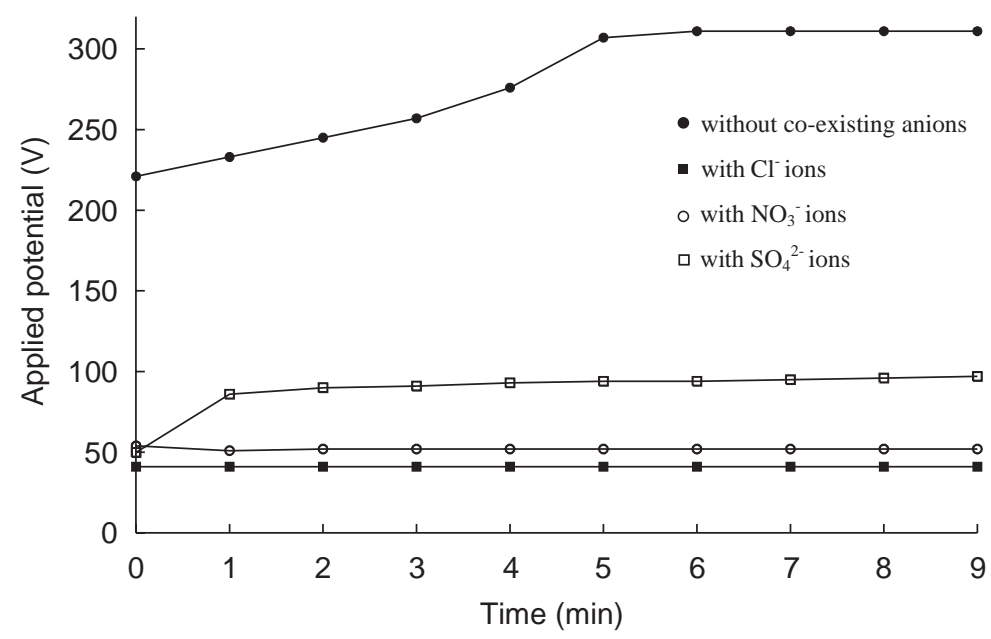

Fig. 5. The variation of applied potential with time in system 1 .

electro-condensation effect. Consequently, the fluoride removal rate per unit of $\mathrm{Al}(\mathrm{III})$ in the solution without co-existing anions was much higher than in other solutions.

\subsection{Effect on applied potential}

Fig. 5 shows the variation of applied potential with time in the EC defluoridation without co-existing anions and with various types of co-existing anions. The applied potential rose in the solution without co-existing anions and in the solution containing both $\mathrm{F}^{-}$and $\mathrm{SO}_{4}^{2-}$ ions but almost remained the same in the solutions that contained both $\mathrm{F}^{-}$and $\mathrm{Cl}^{-}$or $\mathrm{NO}_{3}^{-}$ions. Eq. (7) expresses the applied potential in the EC defluoridation:

$E_{\mathrm{AP}}=n\left(-\Delta E+\eta_{\mathrm{ck}}+\eta_{\mathrm{ak}}+\eta_{\mathrm{cm}}+\eta_{\mathrm{am}}+\eta_{\mathrm{s}}\right)$.

The term $\Delta E$ is the equilibrium reaction potential, which can be calculated by Nernst equation and should not change during such a short reaction $(9 \mathrm{~min})$ in the EC process. The terms $\eta_{\mathrm{cm}}$ and $\eta_{\mathrm{am}}$ are the cathodic and anodic mass-transfer over potential and can be reduced to zero by stirring [14]. Ohm's law (Eq. (8)) determines the potential drop of solution $\left(\eta_{\mathrm{s}}\right)$ :

$\eta_{\mathrm{s}}=I d / A \kappa$.

The current $(I)$, the distance between each electrode $(d)$ and the active electrode area $(A)$ were maintained constant in all systems. Table 2 presents the initial and 
final conductivity in all solutions; they were almost the same. Accordingly, $\eta_{\mathrm{s}}$ in each solution can be regarded as a constant. Thus, the kinetic over potential can be determined by Eq. (9):

$\eta_{\mathrm{k}}=\frac{E_{\mathrm{AP}}}{n}+\left(\Delta E-\eta_{\mathrm{s}}\right)$

Fig. 6 plots the variation of the kinetic over potential with time in system 1 . The kinetic over potential in the solution without co-existing anions rose gradually from 10 to $100 \mathrm{~V}$. This phenomenon may be explained by the growth of the gelatinous, deposited layer on the surface of the anode that increases the resistance. While the kinetic over potential in the solution that contained both $\mathrm{F}^{-}$and $\mathrm{SO}_{4}^{2-}$ ions rose rapidly from 30 to $70 \mathrm{~V}$ and after reaching $70 \mathrm{~V}$, a nearly constant kinetic over-potential was observed, indicating that the properties of the passive film changed very fast then maintained during the EC defluoridation process.

The above results explain why $\varepsilon_{\mathrm{c}}$ decreased as the concentration of $\mathrm{SO}_{4}^{2-}$ increased. Some of the current flowed though the solution, bypassing the bipolar electrodes and decreasing $\varepsilon_{\mathrm{c}}$ because the kinetic over potential of anodes in the solutions that contained both $\mathrm{F}^{-}$and $\mathrm{SO}_{4}^{2-}$ ions was very high. The bypass flow as a proportion of the total current depends on the resistance of bipolar electrodes and the conductivity of the solutions. If the conductivity of the solution increases, then the bypass flow will also increase. As shown in Table 2, increasing $\mathrm{SO}_{4}^{2-}$ concentration increases the conductivity of the solution. Therefore, $\varepsilon_{\mathrm{c}}$ drops as the concentration of $\mathrm{SO}_{4}^{2-}$ increases.

\subsection{Potentiodynamic polarization test}

Fig. 7 presents potentiodynamic polarization curves for various solutions. The polarization curves can be used to discriminate whether the pitting occurs. The current density rises slowly before pitting occurs and rises dramatically as the pitting initiates. The critical potential at which pitting initiates can be defined as pitting potential. In the absence of co-existing anions, no obvious pitting was observed and a similar phenomenon was observed in the solution that contained both $\mathrm{F}^{-}$and $\mathrm{SO}_{4}^{2-}$ ions. In contrast, in the presence of $\mathrm{Cl}^{-}$and $\mathrm{NO}_{3}^{-}$ ions, the current density appeared to be constant below the pitting potential and rose remarkably as the applied potential increased above the pitting potential. Moreover, the pitting potential in the solution that contained both $\mathrm{F}^{-}$and $\mathrm{NO}_{3}^{-}$ions exceeded that in the solution that contained both $\mathrm{F}^{-}$and $\mathrm{Cl}^{-}$ions. Therefore, a higher applied potential is required to initiate rapid localized corrosion in solutions that contain both $\mathrm{F}^{-}$and $\mathrm{NO}_{3}^{-}$ ions. This fact may be due to the greater affinity of $\mathrm{Cl}^{-}$ions for $\mathrm{Al}(\mathrm{III})$. As mentioned earlier, the lyotropic series of the anions for $\mathrm{Al}$ (III) is $\mathrm{F}^{-}>\mathrm{SO}_{4}^{2-} \gg \mathrm{Cl}^{-}>\mathrm{NO}_{3}^{-}$[19-23]. Thus, a higher potential is needed to initiate local adsorption in the solution containing both $\mathrm{F}^{-}$and $\mathrm{NO}_{3}^{-}$ions. Furthermore, although the affinity of $\mathrm{F}^{-}$or $\mathrm{SO}_{4}^{2-}$ ions for $\mathrm{Al}$ (III) is greater than $\mathrm{Cl}^{-}$ions, perhaps because of the lower solubility of the fluoro-hydro-aluminum and sulfahydro-aluminum complex, there is no obvious pitting occurred. Therefore, the over-potential were very high in the solution without co-existing anions and the solution containing both $\mathrm{F}^{-}$and $\mathrm{SO}_{4}^{2-}$ ions. The same phenomenon occurs in the alkaline solution [18]. It should be

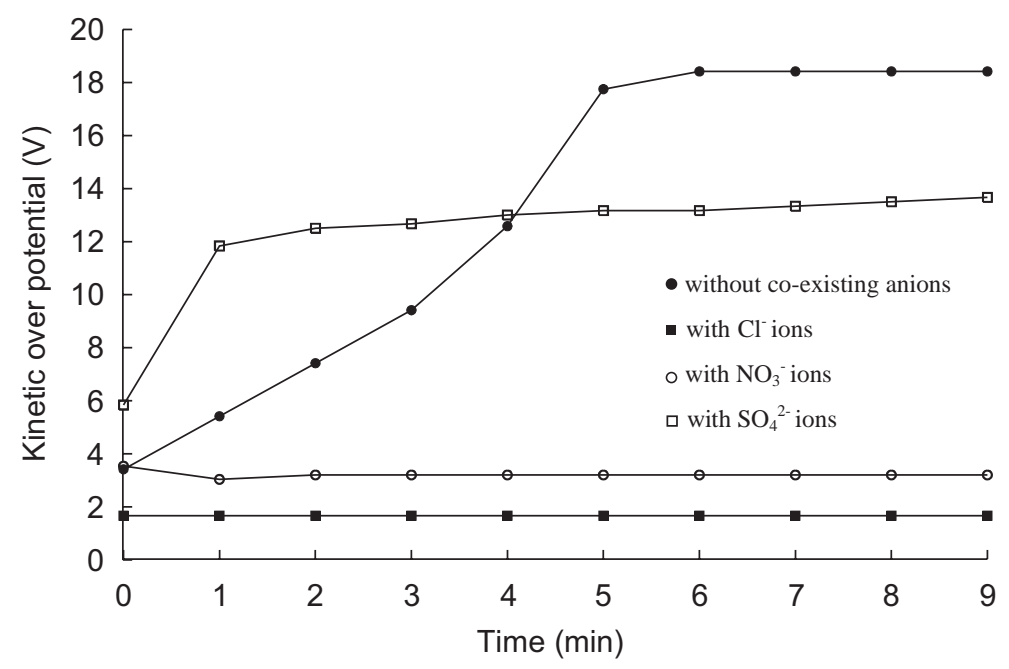

Fig. 6. The variation of the kinetic over potential with time in system 1. 


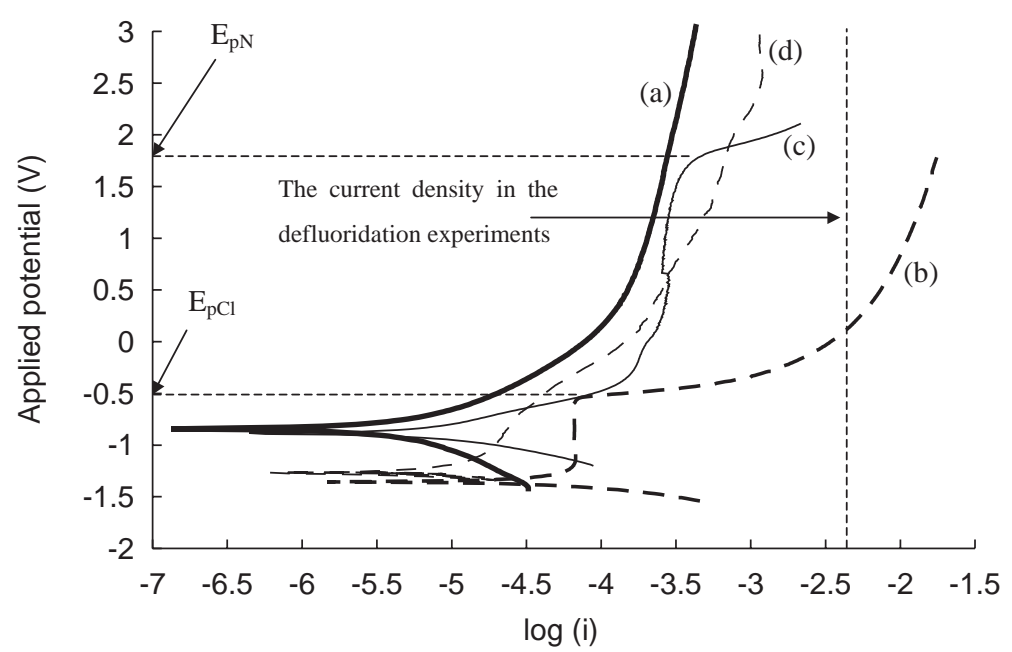

Fig. 7. The potentiodynamic polarization curves for various solutions: (a) solution without co-existing anion, (b) solution that contained both $\mathrm{F}^{-}$and $\mathrm{Cl}^{-}$ions, (c) solution that contained both $\mathrm{F}^{-}$and $\mathrm{NO}_{3}^{-}$ions, (d) solution that contained both $\mathrm{F}^{-}$and $\mathrm{SO}_{4}^{2-}$ ions. The $E_{\mathrm{pN}}$ is the pitting potential in the solution containing both $\mathrm{F}^{-}$and $\mathrm{NO}_{3}^{-}$ions, and the $E_{\mathrm{pCl}}$ is in the solution containing both $\mathrm{F}^{-}$and $\mathrm{Cl}^{-}$ions.

due to the fluoride and hydroxyl ions have similar size and affinity with $\mathrm{Al}(\mathrm{III})$.

The results of the potentiodynamic polarization test agreed with the results in Fig. 6. The kinetic over potential of each solution in Fig. 6 can be regarded as the applied potential in Fig. 7 at the current density $\left(5.56 \times 10^{-3} \mathrm{~A} / \mathrm{cm}^{2}\right)$ in the defluoridation experiments. The kinetic over potential in the solution without pitting was much greater than in the solutions with pitting. Accordingly, the kinetic over potential was much higher in the solution without co-existing anion and the solution containing both $\mathrm{F}^{-}$and $\mathrm{SO}_{4}^{2-}$ ions than in solutions containing both $\mathrm{F}^{-}$and $\mathrm{Cl}^{-}$or $\mathrm{NO}_{3}^{-}$ions. Furthermore, because the pitting potential in the solution that contained both $\mathrm{F}^{-}$and $\mathrm{Cl}^{-}$ions was much less than in the solution that contained both $\mathrm{F}^{-}$and $\mathrm{NO}_{3}^{-}$ions $\left(-0.5 \mathrm{~V}\right.$ for $\mathrm{Cl}^{-}$and $1.8 \mathrm{~V}$ for $\left.\mathrm{NO}_{3}^{-}\right)$, the kinetic over potential in solution containing both $\mathrm{F}^{-}$ and $\mathrm{NO}_{3}^{-}$ions was higher than that in solution containing both $\mathrm{F}^{-}$and $\mathrm{Cl}^{-}$ions.

Fig. 8 displays the SEM images of the anode's surface before (Fig. 8a) and after potentiodynamic polarization tests. The results were coincident with those of the potentiodynamic polarization tests. Rare obvious localized pitting occurred on the anode's surface in the absence of coexisting anions (Fig. 8b) or in the presence of $\mathrm{SO}_{4}^{2-}$ ions (Fig. 8e). This phenomenon shows that the rate of corrosion is almost the same on all parts of the surface of the electrode. Therefore, the electrodes corrode uniformly. Pitting corrosion occurred in the presence of $\mathrm{Cl}^{-}$ions (Fig. 8c). Numerous pits were distributed on the surface of the anode but other parts of the surface were smooth, implying that the corrosion is localized in the solution that contain both $\mathrm{F}^{-}$and $\mathrm{Cl}^{-}$ ions. Crevice corrosion occurred in the presence of $\mathrm{NO}_{3}^{-}$ ions (Fig. 8d). A film with many flaws covered the anode's surface. The corrosion types of the two solutions $\left(\mathrm{Cl}^{-}\right.$and $\left.\mathrm{NO}_{3}^{-}\right)$were different because of the different chemical reactions that occurred when the bare metal was exposed to the different solutions. The $\mathrm{pH}$ of the solution that contained both $\mathrm{F}^{-}$and $\mathrm{Cl}^{-}$ions in the pits, was 3-4 [26] due to the hydrolysis of the $\mathrm{Al}(\mathrm{III})$ (Eqs. (10) and (11)):

$$
\begin{aligned}
& \mathrm{Al}_{(\mathrm{s})} \rightarrow \mathrm{Al}_{(\mathrm{aq})}^{3+}+3 \mathrm{e}^{-} \quad \Delta E^{0}=1.71 \mathrm{~V}, \\
& \mathrm{Al}_{(\mathrm{aq})}^{3+}+\mathrm{H}_{2} \mathrm{O}_{(\mathrm{l})} \rightarrow \mathrm{H}_{(\mathrm{aq})}^{+}+\mathrm{AlOH}_{(\mathrm{aq})}^{2+} .
\end{aligned}
$$

The oxide film is soluble at such a low $\mathrm{pH}$ value. Therefore, the oxide film near the pits dissolved. In the presence of $\mathrm{NO}_{3}^{-}$ions, however, the electrochemical reduction of $\mathrm{NO}_{3}^{-}$ions (Eqs. (12)-(14)) occurred [24,27]:

$$
\begin{aligned}
& 3 \mathrm{NO}_{(\mathrm{aq})}^{3-}+3 \mathrm{H}_{2} \mathrm{O}_{(\mathrm{l})}+2 \mathrm{Al}_{(\mathrm{s})} \rightarrow 2 \mathrm{Al}_{(\mathrm{aq})}^{3+} \\
& +3 \mathrm{NO}_{2(\mathrm{aq})}^{-}+6 \mathrm{OH}_{(\mathrm{aq})}^{-} \quad \Delta E^{0}=1.72 \mathrm{~V}, \\
& 6 \mathrm{NO}_{(\mathrm{aq})}^{3-}+18 \mathrm{H}_{2} \mathrm{O}_{(\mathrm{l})}+10 \mathrm{Al}_{(\mathrm{s})} \rightarrow 10 \mathrm{Al}_{(\mathrm{aq})}^{3+} \\
& \quad+3 \mathrm{~N}_{2(\mathrm{~g})}+36 \mathrm{OH}_{(\mathrm{aq})}^{-} \quad \Delta E^{0}=1.97 \mathrm{~V}, \\
& 3 \mathrm{NO}_{(\mathrm{aq})}^{3-}+18 \mathrm{H}_{2} \mathrm{O}_{(\mathrm{l})}+8 \mathrm{Al}_{(\mathrm{s})} \rightarrow 8 \mathrm{Al}_{(\mathrm{aq})}^{3+} \\
& \quad+3 \mathrm{NH}_{3(\mathrm{aq})}+27 \mathrm{OH}_{(\mathrm{aq})}^{-} \quad \Delta E^{0}=1.59 \mathrm{~V} .
\end{aligned}
$$

All of the above reactions produce $\mathrm{OH}^{-}$ions. Therefore, the oxide film over the crevices did not dissolve but sometimes became thick following the precipitation of $\mathrm{Al}(\mathrm{OH})_{3}$ (Eq. (12)):

$\mathrm{Al}_{(\mathrm{aq})}^{3+}+3 \mathrm{OH}_{(\mathrm{aq})}^{-} \rightarrow \mathrm{Al}(\mathrm{OH})_{3(\mathrm{~s})}$. 

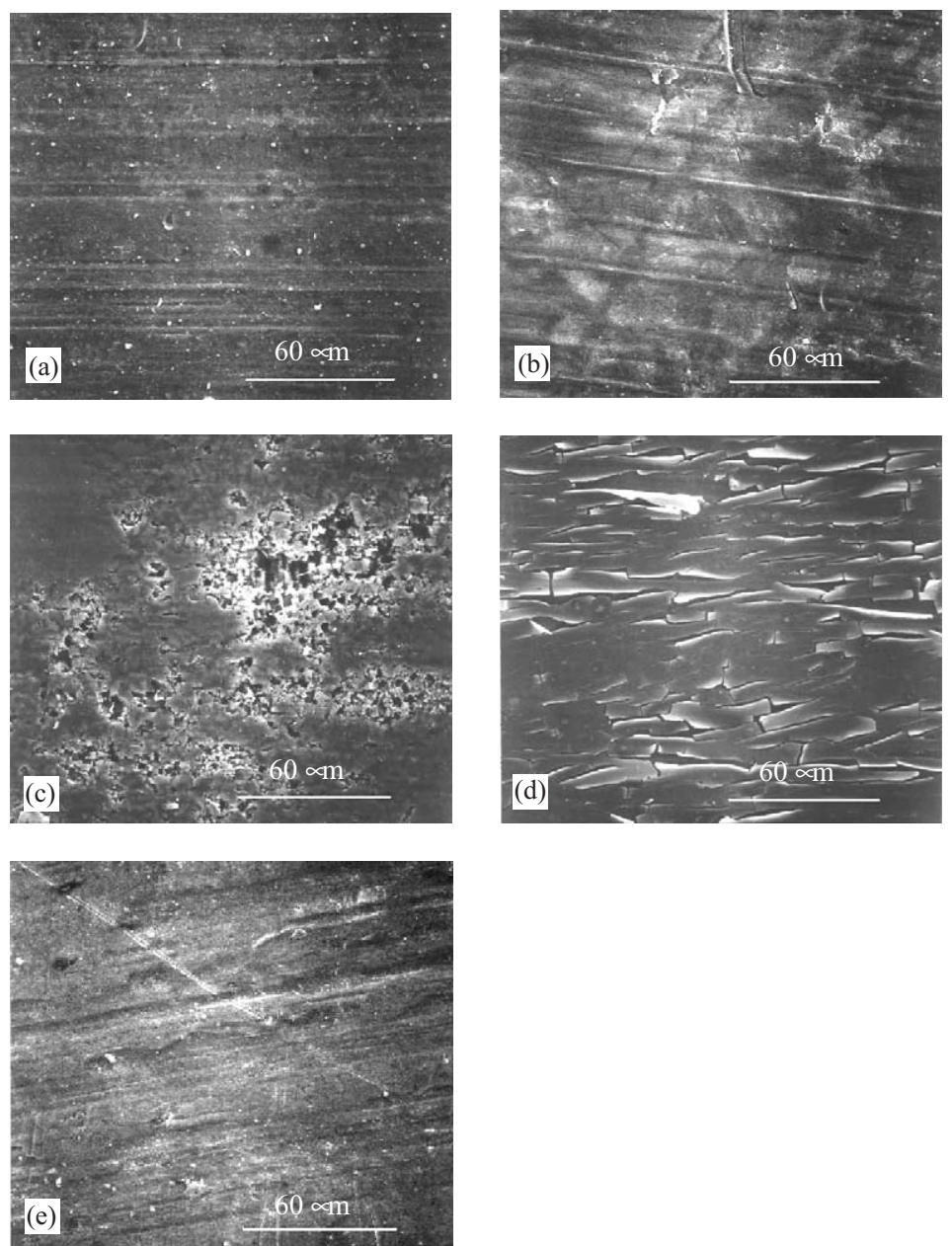

Fig. 8. Electron micrographs of the anode's surface before and after potentiodynamic polarization tests in various solution: (a) original surface (b) solution without co-existing anion, (c) solution that contained both $\mathrm{F}^{-}$and $\mathrm{Cl}^{-}$ions, (d) solution that contained both $\mathrm{F}^{-}$and $\mathrm{NO}_{3}^{-}$ions, (e) solution that contained both $\mathrm{F}^{-}$and $\mathrm{SO}_{4}^{2-}$ ions.

\section{Conclusion}

The types and concentrations of co-existing anions play important roles in EC defluoridation system. The defluoridation reaction occurs on the surface of the anode in the solution without co-existing anions due to the electro-condensation effect and the defluoridation efficiency are near $100 \%$ in this system. In the system with co-existing anions, the defluoridation reaction takes place in bulk solution and the residual fluoride concentration is controlled by $\mathrm{Al}(\mathrm{III})$ dosage. Different types of corrosion of aluminum may occur in different anion-containing solutions. The type of corrosion of aluminum affects the kinetic over potential. A high kinetic over potential leads to a bypass current in the bipolar EC system and the bypass flow as a proportion of total current is influenced by the kinetic over potential and the conductivity of the solution.
Knowledge of the chemical properties of the passive film is very important for applying the EC process. Corrosion engineers have been devoted to this field for many years. They are interested in preventing corrosion but the information that required for performing the EC process is how to initiate the corrosion efficiently and steadily. Further research is needed to yield a more complete understanding of the mechanism of the EC process. The effects of $\mathrm{pH}$, temperature, alkalinity and pressure should be considered.

\section{Acknowledgements}

The authors thank the National Science Council of Taiwan for financial support of this work under contract NSC-90-2211-E-002-043. 


\section{References}

[1] Brown WE, Gregry JM, Chow LC. Effects of fluoride on emanal solubility and cariostasis. Caries Res 1977;11: 118-41.

[2] Lynch CF. Relationship of fluorine in drinking waters to other drinking waters parameters. Arch Environ Health 1987;42:5-13.

[3] Nell JA, Livanos G. Effects of fluoride concentration in seawater on growth and fluoride accumulation by Sydney rock oyster (Saccostrea commercialis) and flat oyster (Ostrea angasi) spat. Water Res 1988;22:749-53.

[4] Mansson AR, Withford GM. Environmental and physiological factors affecting dental fluorides. J Dent Res 1990;69:706-13.

[5] Buffle J, Parthasarathy N, Haerdi W. Importance of speciation methods in analytical control of water treatment processes with application to fluoride removal from waste water. Water Res 1985;19:7-23.

[6] Huang CJ, Liu JC. Precipitation flotation of fluoridecontaining wastewater from semi-conductor manufacture. Water Res 1999;33:3403-12.

[7] Parthasarathy N, Buffle J, Haerdi W. Combined use of calcium salts and polymeric aluminium hydroxide for defluoridation of waste waters. Water Res 1986;20:443-8.

[8] Choi WW, Chen KY. The removal of fluoride from waste waters by adsorption. J Am Water Works Assoc 1979;71:562-70.

[9] Hao OJ, Huang CP. Adsorption characteristics of fluoride onto hydrous alumina. J Environ Eng 1986;112:1054-69.

[10] Lui M, Sun RY, Zhang JH, Bina Y, Wei L, Lui P, Keichero F. Elimination of excess fluoride in potable water with coarcervation by electrolysis using aluminum anode. Fluoride 1983;20:54-63.

[11] Sun LC. Electrochemical method to remove fluorine from drinking water. Water Supply 1985;3:177-86.

[12] Mameri N, Yeddou AR, Lounici H, Belhocine D, Grib H, Bariou B. Defluoridation of Septentrional Sahara Water of North Africa by electro-coagulation process using bipolar aluminium electrode. Water Res 1998;32:604-12.

[13] Mollah MYA, Schennach R, Parga JR, Cocke DL. Electro-coagulation (EC)-science and applications. J Hazardous Mater 2001;B84:29-41.
[14] Vik EA, Carlson DA, Eikum AS, Gjessing ET. Electrocoagulation of potable water. Water Res 1984;18: 1355-60.

[15] Jones DJ. Principles and prevention of corrosion, 2nd ed. Upper Saddle River, NJ, USA: Prentice-Hall; 1996.

[16] Foley RT. Localized corrosion of aluminum alloys-a review. Corrosion 1986;42:277-88.

[17] Carroll WM, Murphy M, Breslin B. The corrosion/ dissolution behaviour of aluminium in solutions containing both chloride and fluoride ions. Corrosion Sci 1993;34:1495-510.

[18] Pyun S-I, Moon S-M, Ahn S-H, Kim S-S. Effects of $\mathrm{Cl}^{-}$, $\mathrm{NO}_{3}^{-}$, and $\mathrm{SO}_{4}^{2-}$ ions on anodic dissolution of pure aluminum in alkaline solution. Corrosion Sci 1999;41:653-67.

[19] Huang PM, Jackson ML. Fluoride interaction with clays in relation to third byffer range. Nature 1966;211:779-80.

[20] Hingston FJ, Atkinson RJ, Posner AM, Quirk JP. Specific adsorption of anions. Nature 1967;215:1459-61.

[21] Hingston FJ, Atkinson RJ, Posner AM, Quirk JP. Anion adsorption by geothite and gibbsite. I. The role of the proton in determining adsorption envelopes. J Soil Sci 1972;23:177-92.

[22] Hingston FJ, Atkinson RJ, Posner AM, Quirk JP. Anion adsorption by geothite and gibbsite. II. Desorption of anions from hydrous oxide surfaces. J Soil Sci 1974;25: $16-26$.

[23] Venkataramani B, Venkateswarlu KS, Shankar J. Sorption properties of oxides. IV. Hydrous mixed oxides. J Colloid Interface Sci 1980;76:1-6.

[24] Koparal AS, Ogutveren UB. Removal of nitrate from water by electroreduction and electrocoagulation. J Hazardous Mater 2002;B89:83-94.

[25] Beccaria AM, Poggi G. Aluminum corrosion in slightly alkaline sodium sulfate solutions at different hydrostatic pressure. Corrosion 1987;43:153-8.

[26] Wong KP, Alkire RC. Local chemistry and growth of single corrosion pits in aluminum. J Electrochem Soc 1990;137:3010-5.

[27] Nguyen TH, Foley RT. The chemical nature of aluminum corrosion III. The dissolution mechanism of aluminum oxide and aluminum powder in various electrolytes. J Electrochem Soc 1980;127:2563-6. 